\title{
Understanding stakeholder preferences for managing red foxes in different situations
}

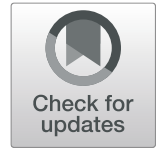

Vasilios Liordos ${ }^{*}$ (I), Vasileios J. Kontsiotis and Foteini Emmanouilidou

\begin{abstract}
Background: Red foxes (Vulpes vulpes) have historically been interacting with human societies, thus being an important component of socio-ecological systems. In Greece, farmers and hunters have been increasingly complaining about predation of red foxes on livestock and game, and the recurrence of rabies incidents has raised concerns about human and animal health. Understanding public preferences about management is necessary for successful wildlife management. This study aimed at investigating the preferences of north Greece residents for managing the negative impacts of red foxes and also at understanding variation between stakeholder groups: farmers, hunters, farmers-hunters, and the general public. Data were collected from on-site face-to-face surveys $(n=746)$, between March and May 2017. Respondents were asked to rate their acceptability of management strategies under three impact scenarios: red foxes attack livestock, reduce game, and carry rabies.

Results: Stakeholders preferred nonlethal management strategies, with generally high consensus, both between and within groups. Fencing and compensation were the most acceptable strategies for protecting livestock and vaccination and the removal of sick animals for eliminating rabies. Acceptability and consensus for lethal strategies were lower, with hunting being the most acceptable lethal strategy for hunters, especially when foxes threatened game or carried rabies. Doing nothing was becoming more unacceptable and lethal control more acceptable with increasing severity of the impacts, i.e., livestock and game predation versus rabies transmission.

Conclusions: Variation in the acceptability of and consensus for management strategies was considerable among scenarios, and both between and within stakeholder groups. Research implications could be used as a guide for reaching consensus for proper management strategies during the conservation conflict management process in the study area. As similar studies are scarce, findings might also prove useful elsewhere, especially in the northern hemisphere where native populations do occur. Findings about managing rabid red foxes would be particularly useful for countries where rabies has not been eliminated, particularly for neighboring Balkan and Asia Minor countries. Findings about managing red fox impacts on livestock and game would be most useful for European countries and especially Mediterranean countries with social and ecological conditions similar to Greece.
\end{abstract}

Keywords: Canids, Farmers, Hunters, Potential for conflict index, Conservation conflict management, Northeast Mediterranean

\section{Background}

Human-wildlife conflict occurs "when the needs and behavior of wildlife impact negatively on the goals of humans or when the goals of humans negatively impact the needs of wildlife" (Madden 2004, p. 248). The use of

\footnotetext{
*Correspondence: liordos@for.ihu.gr

Department of Forestry and Natural Environment, International Hellenic University, P.O. Box 172, 66100 Drama, Greece
}

this term has been criticized as detrimental to coexistence between humans and wildlife, in part because it suggests that wildlife species consciously compete with humans (Peterson et al. 2010). Marshall et al. (2007) and Peterson et al. (2010) argued that human-wildlife conflicts are, in essence and most often, "human-human conflicts"; conflicts among humans over wildlife management issues. Redpath et al. (2013) proposed the use of
SpringerOpen (c) The Author(s). 2020 Open Access This article is licensed under a Creative Commons Attribution 4.0 International License, which permits use, sharing, adaptation, distribution and reproduction in any medium or format, as long as you give appropriate credit to the original author(s) and the source, provide a link to the Creative Commons licence, and indicate if changes were made. The images or other third party material in this article are included in the article's Creative Commons licence, unless indicated otherwise in a credit line to the material. If material is not included in the article's Creative Commons licence and your intended use is not permitted by statutory regulation or exceeds the permitted use, you will need to obtain permission directly from the copyright holder. To view a copy of this licence, visit http://creativecommons.org/licenses/by/4.0/. 
an alternative term, conservation conflicts, defined as "situations that occur when two or more parties with strongly held opinions clash over conservation objectives and when one party is perceived to assert its interests at the expense of another" (p. 100). They emphasized that although the term focuses on conflicts between parties over species of conservation interest, the issues involved apply across the full range of conflicts.

Acceptability generally decreases with increasing invasiveness of management strategies (e.g., from the less invasive fencing to the highly invasive shooting; Treves et al. 2006; Heneghan and Morse 2019). It may also differ between wildlife impacts of varying severity, such as damage to crops and property, and disease transmission, and between and within different public groups, like farmers and hunters (Treves et al. 2006; Frank et al. 2015; Sponarski et al. 2015). Kontsiotis et al. (2020) found that Greek hunters were less willing than farmers and the general public to accept the management of game wild boar (Sus scrofa) than of nongame European badger (Meles meles). Liordos et al. (2017) found that the less invasive nonlethal strategies were more acceptable and less controversial than the more invasive lethal strategies in scenarios involving the fouling of urban structures, crop damage, and disease transmission by wildlife species. They also reported that management strategies became increasingly more acceptable and controversial as the severity of scenarios was increased, from the fouling of urban structures to disease transmission. For successfully addressing a conflict, a management strategy should be effective at reducing wildlife impacts and at the same time, all interested parties should support its use (Redpath et al. 2015). Therefore, the understanding of differences in the acceptability of management strategies between and within public groups is necessary (Manfredo 2008).

Red foxes (Vulpes vulpes), hereafter just foxes, are considered attractive animals and people enjoy watching them (König 2008). However, the species' association with human environments has caused impacts of varying severity for centuries, resulting in pest status and wide persecution (Harris and Lloyd 1991; Wilson and Mittermeier 2009). Outdoor livestock farming is extensively practiced in north Greece, and Papageorgiou et al. (1988) found goat kids, lambs, calves, and piglets in fox diet. Also, farmers from north Greece increasingly complain for fox attacks on livestock (Directorate of Animal Husbandry Systems, Hellenic Ministry of Agricultural Development and Food, unpublished data). In Europe, foxes mostly consume rodents, especially microtine rodents (O’Mahony et al. 1999; Pagh et al. 2015). However, Greek hunters have been increasingly blaming a perceived rise in fox numbers for the decline of grey partridge (Perdix perdix) and especially brown hare (Lepus europaeus) populations (Vlachos et al. 2006). Rabies causes each year 55,000 deaths of people worldwide (Tasioudi et al. 2014). Oral vaccination has led to the elimination of fox-mediated rabies from most Western and Central European countries (Freuling et al. 2013), although the disease still occurs in other parts of Europe (Tasioudi et al. 2014). Greece had been rabies-free since 1987 with no human cases since 1970 (Tasioudi et al. 2014). During 2012 to 2013, rabies was diagnosed in 17 animals in north Greece, including 14 foxes, two dogs, and one cat (Tsiodras et al. 2013).

One common strategy to reduce fox impacts is to reduce fox population levels. Commonly used fox population control strategies are snaring (using non-locking neck snares), trapping (with live-capture cage or box traps), culling at denning sites called "earths" (remove females and cubs from earths), hunting as a game during the hunting season, and shooting (at night with a spotlight and rifle: "lamping"; during the day by groups or individuals with scent dogs) (Harris 1985; Heydon and Reynolds 2000; Macdonald et al. 2000). Fencing, both regular and electric, is the most common nonlethal strategy used to prevent fox predation on livestock or hand-reared game (Macdonald et al. 2000). Fencing, hunting as a game, and oral vaccination baits are the strategies most often applied for minimizing fox impacts in Greece (Birtsas et al. 2008; Tasioudi et al. 2014).

Public preferences for managing fox impacts have received little attention in their natural range. König (2008) examined the opinions of a Munich suburb's residents towards the management of fox tapeworm (Echinococcus multilocularis), and Delibes-Mateos et al. (2013) evaluated the attitudes and behavior of game managers with regard to fox management in Central Spain. We studied stakeholder preferences for managing red foxes in north Greece. As livestock farmers, hereafter just farmers, and hunters are the public groups most affected by foxes, we identified four stakeholder groups, based on farmer and/or hunter membership: (1) the general public, including those being neither farmers nor hunters, but having a possibility to encounter a rabid animal in the area; (2) farmers; (3) hunters; and (4) farmers-hunters. Our first objective was to investigate the degree of acceptability by stakeholder groups of different management strategies when foxes: (1) attack livestock, (2) reduce game, and (3) carry rabies. Opinions concerning a management strategy may or may not differ among individuals and groups. Knowing the level of agreement or disagreement among individuals and groups can help managers take appropriate measures to alleviate social conflict over proposed management strategies. Our second objective was therefore to estimate the potential for conflict or consensus about different 
management strategies, both between and within stakeholder groups.

Based on our objectives and previous research, we hypothesized the following:

- $\mathrm{H}_{1}$. Acceptability and consensus both differ between stakeholder groups in each management strategy.

- $\mathrm{H}_{2}$. Acceptability and consensus both decrease with increasing invasiveness of the management strategies.

- $\mathrm{H}_{3}$. Acceptability increase and consensus decrease for each management strategy with increasing severity of the impact.

\section{Methods}

\section{Sampling}

North Greece includes the Districts of Western, Central and Eastern Macedonia, and Thrace (Fig. 1), an area with a population of roughly $2,774,000$ people (ELSTAT 2011). Data were collected from on-site face-to-face surveys with north Greece residents, between March and May 2017. A pretest of the survey $(n=20$ random people) was conducted to test question clarity and completion time. Cities, towns, and villages were visited in all the districts during open market hours (9.00-15.00 and 17.00-21.00, from Monday to Saturday). People in most neighborhoods were surveyed, in both poorer and wealthier areas, in an effort to assemble a demographically representative sample. Every fifth person passing in front of the researcher was asked to participate by completing a questionnaire (Vaske 2008). In cases in which more than five persons had passed while a questionnaire was being completed, the first person encountered upon completion was selected. Farmers' cooperatives and hunting clubs within the study area were also visited to ensure representation of farmers and hunters in the sample. It took respondents $10 \mathrm{~min}$ on average to orally complete the questionnaire with the assistance of the interviewer.

\section{Questionnaire development}

Survey participants were classified in a stakeholder group, i.e., general public, farmers, hunters, or farmershunters, and were then asked a series of questions about

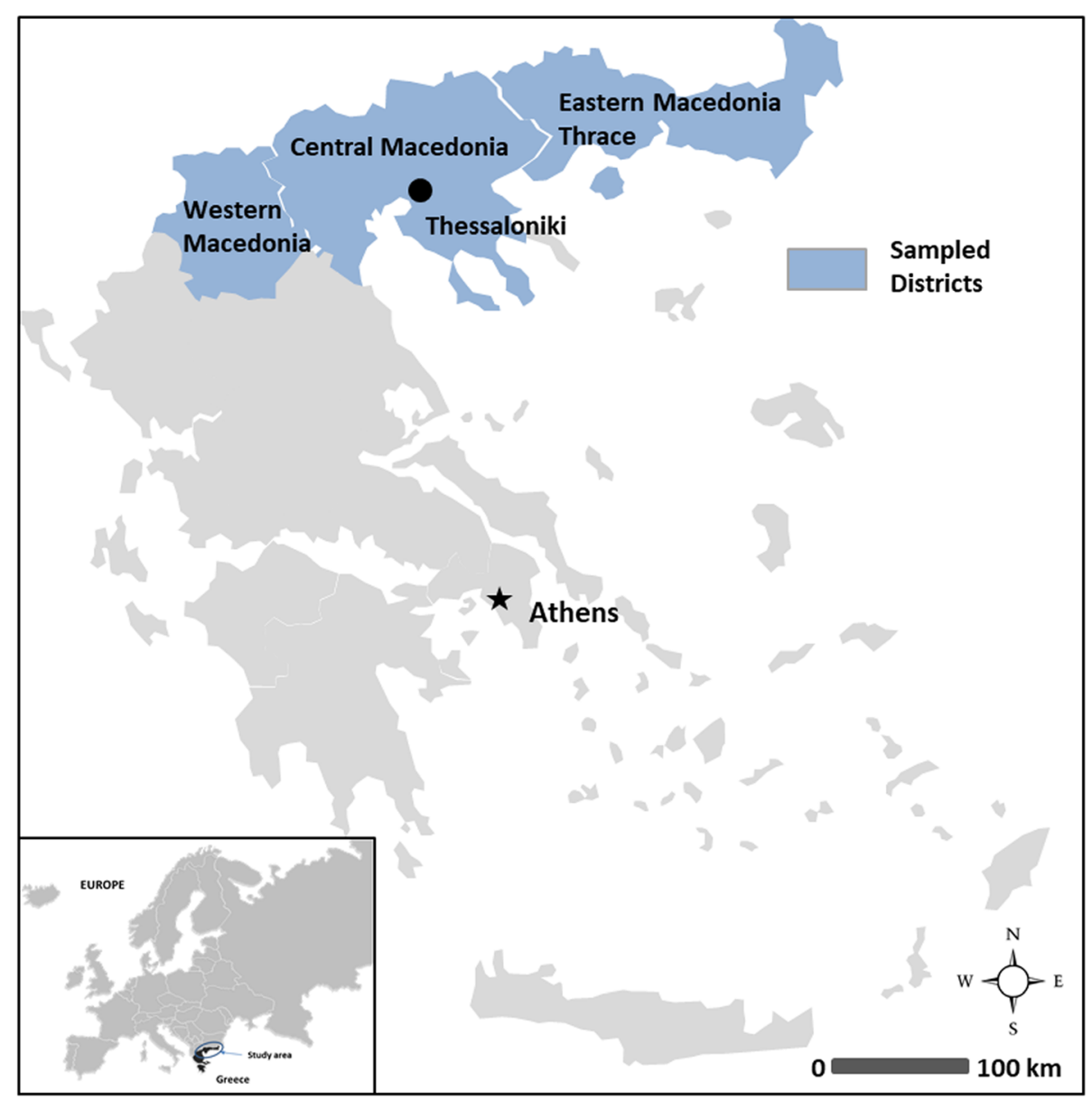

Fig. 1 Map showing the region of Greece in which the study was carried out 
demographic characteristics and the acceptability of management strategies. Demographic characteristics included gender (female and male) and age (aggregated into three classes of adults ( $\geq 18$ years of age), following the classification by ELSTAT (2011): 18-34 years old, $35-54$ years old, and 55 and over years old.

Subsequently, three impact scenarios were offered: (1) foxes attack livestock (e.g., lambs, poultry); (2) foxes reduce game populations, such as brown hare and grey partridge; and (3) foxes carry rabies. Under each of these scenarios, five management strategies were offered. Survey questions were structured as, using scenario 1 as an example, "Foxes often roam human settlements and feed on livestock, such as lambs and poultry. When they cause significant damage, how acceptable or unacceptable would be for you to (1) take no action, (2) cull at denning sites (remove females and cubs from dens), (3) reduce populations using trapping or snaring, (4) reduce populations through hunting (as a game species), and (5) reduce populations through shooting (at night with a spotlight and rifle (lamping); during the day by groups or individuals)". Participants were then asked to rate each management strategy on a 5-point scale as "highly unacceptable" (-2), "unacceptable" (-1), "neither" (0), "acceptable" (1), or "highly acceptable" (2). The same rating scale was used for all scenarios. The rating of two additional strategies was asked for each of scenarios 1 and 3: compensation for economic damage and use of fencing for the protection of livestock (scenario 1) and oral vaccination and the killing of sick animals for eliminating rabies (scenario 3).

\section{Data analysis}

One-way analysis of variance (ANOVA) was used to compare the overall mean responses for each scenario in each management strategy and the mean responses of stakeholder groups to each of the management strategies in each scenario. Repeated-measures ANOVA was used to compare mean responses within each management strategy across the five scenarios for each stakeholder group. Significant differences between groups were determined with pairwise Tamhane post hoc tests to account for heteroscedasticity, applying Bonferroni correction to adjust for multiple testing.

Measures of consensus include standard deviation and coefficient of variation (Krymkowski et al. 2009). These measures, however, do not have an upper and lower bound, making it difficult to interpret findings (Engel et al. 2017). The potential for conflict index $\left(\mathrm{PCI}_{2}\right)$ was developed to help address these issues (Vaske et al. 2010). $\mathrm{PCI}_{2}$ ranges from 0 to 1 . The least amount of consensus and the greatest potential for conflict $\left(\mathrm{PCI}_{2}=\right.$ 1) occurs when responses are equally divided between two extreme values on a response scale (e.g., 50\% highly unacceptable, $50 \%$ highly acceptable). A distribution with $100 \%$ at any one point on the response scale yields a $\mathrm{PCI}_{2}$ of 0 and suggests complete consensus and no potential for conflict. $\mathrm{PCI}_{2}$ results can be visualized in bubble graphs (Vaske et al. 2010). The center of a bubble represents mean acceptability of a particular issue by the public or segments of the public (e.g., farmers, hunters), while the size of the bubble depicts the magnitude of the $\mathrm{PCI}_{2}$ and indicates the degree of potential conflict (or consensus) regarding the acceptability of that issue. $\mathrm{PCI}_{2}$ was calculated for each of the management strategies and the four stakeholder groups, under each scenario, and differences were tested with pairwise $d$ tests (Vaske et al. 2010) with Bonferroni correction.

One-way and repeated-measures ANOVAs were performed in SPSS Statistics (version 21.0, IBM Corp., 2012) and $\mathrm{PCI}_{2}$ statistics were calculated using free online software (https://sites.warnercnr.colostate.edu/jer ryv/calculating-pci2-excel/). The significance level was set at $\alpha=0.0167$ (three comparisons) or 0.0083 (six comparisons) after Bonferroni correction.

\section{Results \\ Demographics}

A total of 746 questionnaires were completed, with 73 refusals, yielding a response rate of $91 \%$. The study area's population has a $51 \%$ female $/ 49 \%$ male gender ratio, and the age ratio, after excluding those under 18 , is $30 \% /$ $36 \% / 34 \%$ in the $18-34,35-54$, and 55+-year-old age classes, respectively. The sample's gender and age structure was not different to that of the population's (comprised of four stakeholder groups: the general public, farmers, hunters, and farmers-hunters; Table 1; gender: $\chi^{2}=0.243, d f=1, p=0.569$; age: $\chi^{2}=4.591, d f=$ $2, p=0.101)$.

\section{Overall acceptability and consensus}

Overall results revealed low acceptability by the survey participants for taking no action in impact management (Table 2, Fig. 2). Acceptability was also lower for more invasive strategies than for less invasive strategies in all the scenarios. The no action option was significantly more unacceptable $(p<0.0167$; pairwise Tamhane post hoc tests with Bonferroni correction) and less controversial $(p<0.0167$; pairwise $d$ tests with Bonferroni correction) among participants when foxes carry rabies (scenario 3; mean acceptability $M=-1.45, \mathrm{PCI}_{2}=0.06$ ) than when they attack livestock (scenario $1 ; M=-0.80$, $\mathrm{PCI}_{2}=0.29$ ) and reduce game populations (scenario 2; $M=-0.17, \mathrm{PCI}_{2}=0.43$ ) (Table 2, Fig. 2). Invasive strategies, i.e., culling at the den, trapping or snaring, and hunting and shooting, were unacceptable by the participants in all the scenarios. However, although unacceptable, invasive strategies were significantly less so in the 
Table 1 Sociodemographic characteristics of the survey participants $(n=746)$

\begin{tabular}{|c|c|c|c|c|c|}
\hline & Total & General public & Farmers & Hunters & Farmers-hunters \\
\hline \multicolumn{6}{|l|}{ Age } \\
\hline $18-34$ & $226(30)$ & $136(35)$ & $47(29)$ & $26(24)$ & $19(24)$ \\
\hline $35-54$ & $245(33)$ & $129(33)$ & $63(38)$ & $32(28)$ & $20(26)$ \\
\hline $55+$ & $275(37)$ & $127(32)$ & $54(33)$ & $54(48)$ & $39(50)$ \\
\hline \multicolumn{6}{|l|}{ Gender } \\
\hline Female & $389(52)$ & $277(71)$ & $115(70)$ & $0(0)$ & $0(0)$ \\
\hline Male & $357(48)$ & $115(29)$ & $49(30)$ & $112(100)$ & $78(100)$ \\
\hline
\end{tabular}

Note: Column frequencies and percentages (in parentheses) by age and gender categories in total and in each stakeholder group

most severe scenario, foxes carry rabies (culling at the den: $M=-0.47$, trapping or snaring: $M=-0.92$, hunting: $M=-0.59$, shooting: $M=-1.13)$ than the other scenarios (foxes attack livestock, culling at the den: $M=-1.03$, trapping or snaring: $M=-1.25$, hunting: $M=-0.99$, shooting: $M=-1.46$; foxes reduce game, culling at the den: $M=-0.91$, trapping or snaring: $M=-1.15$, hunting: $M=-0.82)(p<0.0167)$. The level of consensus for the more invasive strategies varied from high to medium (Fig. 2). The consensus was significantly lower for hunting when foxes carry rabies $\left(\mathrm{PCI}_{2}=0.42\right)$ than when they attack livestock $\left(\mathrm{PCI}_{2}=\right.$ $0.29)$ and also for shooting when foxes carry rabies $\left(\mathrm{PCI}_{2}=0.33\right)$ and reduce game $\left(\mathrm{PCI}_{2}=0.32\right)$ than when they attack livestock $\left(\mathrm{PCI}_{2}=0.17\right)(p<0.0167 ; d$ tests with Bonferroni correction). Less invasive strategies not aiming the reduction of fox populations, such as compensation or fencing (in scenario 1 ), and vaccination or killing rabid foxes (in scenario 3), were acceptable and less controversial among participants.

\section{Differences among stakeholder groups, within scenarios Scenario 1: Foxes attack livestock}

On average, compensation and fencing were acceptable for all stakeholder groups, whereas all other strategies were largely unacceptable (Table 3 , Fig. 3). Taking no action was significantly more acceptable for the general public $(M=-0.60)$ than farmers $(M=-0.96)$ and farmers-hunters $(M=-1.35)(p<0.0083$; Tamhane post hoc tests with Bonferroni correction). Compensation was significantly more acceptable for farmers $(M=1.17)$ and farmers-hunters $(M=1.06)$ than the general public $(M=$ 0.46) ( $p<0.0083)$. Culling at the den, trapping or snaring, and hunting were significantly more unacceptable for the general public $(M=-1.42,-1.63$, and -1.32 , respectively) than the other groups (farmers: $M=-0.79,-1.09$, and -0.87 , respectively; hunters: $M=-0.30,-0.19$, and 0.00 , respectively; farmers-hunters: $M=-0.29,0.00$, and -0.24 , respectively) $(p<0.0083)$. The general public $(M=$ - 1.62) was significantly more negative towards shooting than farmers-hunters $(M=-0.71)(p<0.0083)$. Level of consensus was generally high (i.e., low $\mathrm{PCI}_{2}$ values) for taking no action $\left(\mathrm{PCI}_{2}=0.11-0.32\right)$, compensation $\left(\mathrm{PCI}_{2}\right.$ $=0.09-0.30)$, and fencing $\left(\mathrm{PCI}_{2}=0.05-0.22\right)$, with differences being significant between farmers-hunters $\left(\mathrm{PCI}_{2}=0.09\right)$ and the general public $\left(\mathrm{PCI}_{2}=0.30\right)$ for compensation ( $p<0.0083$; Fig. 3 ). The consensus was lower for lethal strategies, especially between members of the farmer-hunter (culling at the den, $\mathrm{PCI}_{2}=0.37$; trapping or snaring, $\mathrm{PCI}_{2}=0.53$; hunting, $\mathrm{PCI}_{2}=0.60$;

Table 2 Comparisons between impact scenarios regarding the acceptability of red fox management strategies $(n=746)$

\begin{tabular}{|c|c|c|c|c|c|c|}
\hline Management strategy & Scenario 1 (M) & Scenario $2(\mathrm{M})$ & Scenario 3 (M) & $F$ & $p$ & Eta $(\eta)$ \\
\hline No action & $-0.80^{\mathrm{A}}$ & $-0.17^{B}$ & $-1.45^{c}$ & 214.502 & $<0.001$ & 0.432 \\
\hline Compensation & 0.81 & - & - & - & - & - \\
\hline Fencing & 1.67 & - & - & - & - & - \\
\hline Culling at the den & $-1.03^{A}$ & $-0.91^{\mathrm{A}}$ & $-0.47^{B}$ & 34.036 & $<0.001$ & 0.212 \\
\hline Trapping or snaring & $-1.25^{\mathrm{A}}$ & $-1.15^{\mathrm{A}}$ & $-0.92^{B}$ & 14.724 & $<0.001$ & 0.164 \\
\hline Hunting & $-0.99^{A}$ & $-0.82^{\mathrm{A}}$ & $-0.59^{B}$ & 17.664 & $<0.001$ & 0.182 \\
\hline Shooting & $-1.46^{\mathrm{A}}$ & $-1.22^{B}$ & $-1.13^{B}$ & 16.017 & $<0.001$ & 0.170 \\
\hline Vaccination & - & - & 1.47 & - & - & - \\
\hline Kill sick animals & - & - & 0.48 & - & - & - \\
\hline
\end{tabular}

Note: One-way analysis of variance (ANOVA) was used for comparisons. $M=$ mean acceptability. $F=$ the $F$-statistic produced by ANOVA tests. Eta ( $\eta$ ) = effect size, $\eta=0.100$ denotes a minimal relationship, $\eta=0.243$ denotes a typical relationship, and $\eta=0.371$ denotes a substantial relationship (Vaske 2008 ). Scenario 1 , foxes attack livestock; scenario 2, foxes reduce game; scenario 3, foxes carry rabies. For each management strategy, mean responses not sharing a superscript letter (A, B, or C) are significantly different ( $p<0.0167$; Tamhane post hoc tests with Bonferroni correction) 


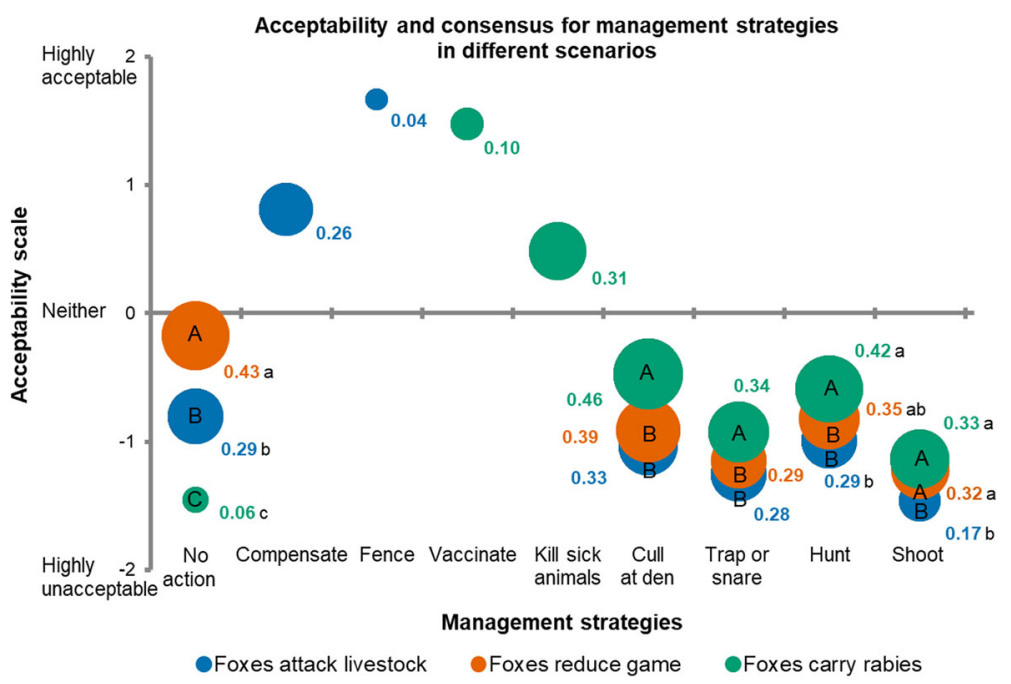

Fig. 2 Mean response scores with potential for conflict indices $\left(\mathrm{PCl}_{2}\right)$, regarding the acceptability of red fox management strategies for 3 impact scenarios. In each management strategy, mean responses (bubble position) and $\mathrm{PCl}_{2}$ values (bubble size) not sharing an uppercase (A, $\mathrm{B}$, or $\mathrm{C}$ ) or lowercase ( $a, b$, or $c)$ letter respectively are significantly different $(p<0.0167$; post hoc Tamhane and $d$ tests with Bonferroni correction)

Table 3 Comparisons between stakeholder groups regarding the acceptability of red fox management strategies $(n=746)$

\begin{tabular}{|c|c|c|c|c|c|c|c|}
\hline Management strategy & General public (M) & Farmers (M) & Hunters (M) & Farmers-hunters (M) & $F$ & $p$ & $\overline{\operatorname{Eta}(\eta)}$ \\
\hline \multicolumn{8}{|c|}{ Scenario 1—foxes attack livestock } \\
\hline No action & $-0.60^{A}$ & $-0.96^{\mathrm{B}}$ & $-0.75^{A B}$ & $-1.35^{B}$ & 7.571 & $<0.001$ & 0.184 \\
\hline Compensation & $0.46^{\mathrm{A}}$ & $1.17^{\mathrm{B}}$ & $0.75^{A B}$ & $1.06^{\mathrm{B}}$ & 24.240 & $<0.001$ & 0.305 \\
\hline Fencing & $1.61^{\mathrm{A}}$ & $1.74^{\mathrm{A}}$ & $1.63^{\mathrm{A}}$ & $1.71^{\mathrm{A}}$ & 2.284 & 0.078 & 0.105 \\
\hline Culling at the den & $-1.42^{\mathrm{A}}$ & $-0.79^{B}$ & $-0.30^{B}$ & $-0.29^{B}$ & 23.895 & $<0.001$ & 0.322 \\
\hline Trapping or snaring & $-1.63^{A}$ & $-1.09^{B}$ & $-0.19^{B}$ & $0.00^{B}$ & 34.717 & $<0.001$ & 0.379 \\
\hline Hunting & $-1.32^{\mathrm{A}}$ & $-0.87^{B}$ & $0.00^{B}$ & $-0.24^{B}$ & 23.056 & $<0.001$ & 0.316 \\
\hline Shooting & $-1.62^{A}$ & $-1.44^{A B}$ & $-1.00^{A B}$ & $-0.71^{\mathrm{B}}$ & 13.057 & $<0.001$ & 0.243 \\
\hline \multicolumn{8}{|c|}{ Scenario 2 -foxes reduce game populations } \\
\hline No action & $0.28^{A}$ & $-0.38^{B}$ & $-1.13^{C}$ & $-1.47^{c}$ & 33.876 & $<0.001$ & 0.375 \\
\hline Culling at the den & $-1.38^{\mathrm{A}}$ & $-0.72^{\mathrm{B}}$ & $0.38^{c}$ & $0.53^{c}$ & 50.303 & $<0.001$ & 0.443 \\
\hline Trapping or snaring & $-1.50^{\mathrm{A}}$ & $-1.10^{\mathrm{B}}$ & $0.19^{c}$ & $0.24^{c}$ & 47.975 & $<0.001$ & 0.434 \\
\hline Hunting & $-1.32^{\mathrm{A}}$ & $-0.81^{B}$ & $1.31^{\mathrm{C}}$ & $1.41^{\mathrm{C}}$ & 121.805 & $<0.001$ & 0.609 \\
\hline Shooting & $-1.57^{\mathrm{A}}$ & $-1.17^{\mathrm{B}}$ & $-0.19^{B C}$ & $0.41^{c}$ & 44.670 & $<0.001$ & 0.422 \\
\hline \multicolumn{8}{|c|}{ Scenario 3-foxes transfer rabies } \\
\hline No action & $-1.41^{\mathrm{A}}$ & $-1.46^{A}$ & $-1.69^{A}$ & $-1.53^{A}$ & 1.634 & 0.180 & 0.089 \\
\hline Vaccination & $1.43^{\mathrm{A}}$ & $1.58^{\mathrm{A}}$ & $1.13^{\mathrm{A}}$ & $1.41^{\mathrm{A}}$ & 2.454 & 0.062 & 0.122 \\
\hline Kill sick animals & $0.12^{\mathrm{A}}$ & $0.80^{B}$ & $0.75^{A B}$ & $0.88^{B}$ & 18.119 & $<0.001$ & 0.285 \\
\hline Culling at the den & $-0.97^{A}$ & $-0.18^{B}$ & $0.63^{B}$ & $0.41^{\mathrm{B}}$ & 32.085 & $<0.001$ & 0.366 \\
\hline Trapping or snaring & $-1.27^{\mathrm{A}}$ & $-0.90^{B}$ & $0.36^{c}$ & $0.65^{c}$ & 46.205 & $<0.001$ & 0.428 \\
\hline Hunting & $-1.01^{\mathrm{A}}$ & $-0.52^{B}$ & $0.88^{C}$ & $1.18^{C}$ & 49.971 & $<0.001$ & 0.442 \\
\hline Shooting & $-1.45^{\mathrm{A}}$ & $-1.08^{B}$ & $-0.06^{c}$ & $0.12^{c}$ & 31.097 & $<0.001$ & 0.362 \\
\hline
\end{tabular}

Note: One-way analysis of variance (ANOVA) was used for comparisons. $M=$ mean acceptability. $F=$ the $F$-statistic produced by ANOVA tests. Eta $(\eta)=$ effect size, $\eta=0.100$ denotes a minimal relationship, $\eta=0.243$ denotes a typical relationship, $\eta=0.371$ denotes a substantial relationship (Vaske 2008). For each management strategy, mean responses from stakeholders not sharing a superscript letter (A, B, or C) are significantly different $(p<0.0083$; Tamhane post hoc tests with Bonferroni correction) 


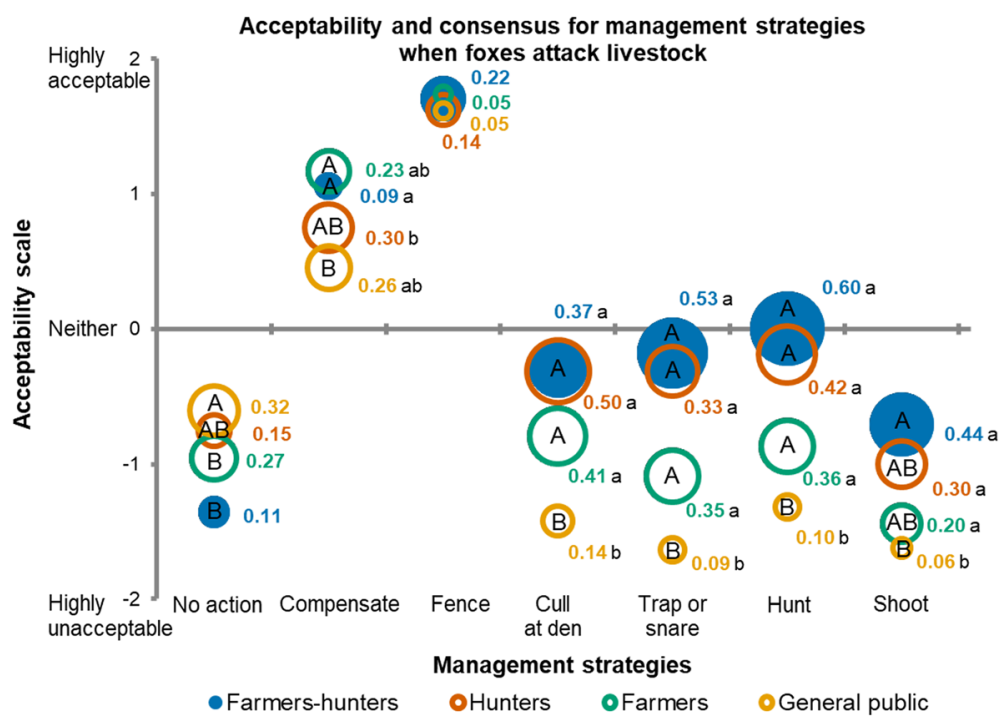

Fig. 3 Mean response scores with potential for conflict indices $\left(\mathrm{PCl}_{2}\right)$ by stakeholder group, regarding the acceptability of management strategies when red foxes attack livestock. In each management strategy, mean responses (bubble position) and $\mathrm{PCl}_{2}$ values (bubble size) not sharing an uppercase (A, B, or $C)$ or lowercase $(a, b$, or $c)$ letter, respectively, are significantly different $(p<0.0083$; post hoc Tamhane and $d$ tests with Bonferroni correction)

shooting, $\mathrm{PCI}_{2}=0.44$ ), hunter (culling at the den, $\mathrm{PCI}_{2}=$ 0.50; trapping or snaring, $\mathrm{PCI}_{2}=0.33$; hunting, $\mathrm{PCI}_{2}=$ 0.42; shooting, $\mathrm{PCI}_{2}=0.30$ ), and farmer (culling at the den, $\mathrm{PCI}_{2}=0.41$; trapping or snaring, $\mathrm{PCI}_{2}=0.35$; hunting, $\mathrm{PCI}_{2}=0.36$; shooting, $\mathrm{PCI}_{2}=0.20$ ) groups. Differences in $\mathrm{PCI}_{2}$ values were significant among the general public (culling at the den, $\mathrm{PCI}_{2}=0.14$; trapping or snaring, $\mathrm{PCI}_{2}=0.09$; hunting, $\mathrm{PCI}_{2}=0.10$; shooting, $\mathrm{PCI}_{2}=0.06$ ) and all other groups for these strategies $(p<0.0083$; $d$ tests with Bonferroni correction).

\section{Scenario 2: Foxes reduce game populations}

The sign of acceptability differed between stakeholder groups in this scenario (Table 3, Fig. 4). Taking no action was slightly acceptable for the general public, shooting was slightly acceptable for farmers-hunters, whereas

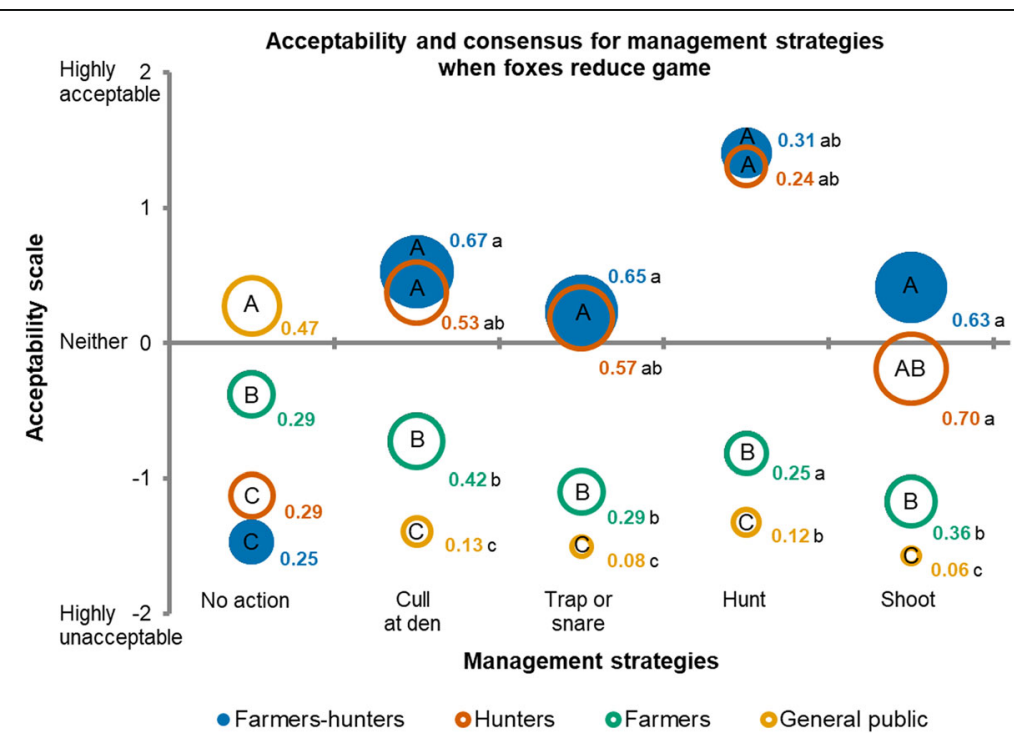

Fig. 4 Mean response scores with potential for conflict indices $\left(\mathrm{PCl}_{2}\right)$ by stakeholder group, regarding the acceptability of management strategies when red foxes reduce game populations. In each management strategy, mean responses (bubble position) and $\mathrm{PCl}_{2}$ values (bubble size) not sharing an uppercase $(\mathrm{A}, \mathrm{B}$, or $\mathrm{C})$ or lowercase $(\mathrm{a}, \mathrm{b}$, or $\mathrm{c})$ letter, respectively, are significantly different $(p<0.0083$; post hoc Tamhane and $d$ tests with Bonferroni correction) 
culling at the den, trapping or snaring, and hunting were acceptable for farmers-hunters and hunters in varying degree. All other groups opposed these management strategies. Taking no action was significantly more acceptable for the general public $(M=0.28)$ than all other groups $(M=-0.38,-1.13$, and -1.47 for farmers, hunters, and farmers-hunters, respectively) and also for farmers than farmers-hunters and hunters $(p<0.0083$; Tamhane post hoc tests with Bonferroni correction). For culling at the den $(M=-1.38,-0.72,0.38$, and 0.53 for the general public, farmers, hunters, and farmershunters, respectively), trapping or snaring $(M=-1.50$, - 1.10, 0.19, and 0.24 for the general public, farmers, hunters, and farmers-hunters, respectively), and hunting $(M=-1.32,-0.81,1.31$, and 1.41 for the general public, farmers, hunters, and farmers-hunters, respectively), mean responses from farmers-hunters and hunters were significantly higher from those of farmers' and the general public's, and of farmers' than the general public's ( $p$ $<0.0083)$. Shooting was significantly more acceptable for farmers-hunters $(M=0.41)$ than farmers $(M=-1.17)$ and the general public $(M=-1.57)$, for farmers than the general public and also for hunters $(M=-0.19)$ than the general public $(p<0.0083)$. The level of consensus was moderately high to moderate for taking no action $\left(\mathrm{PCI}_{2}=0.25-0.47\right)$, with no significant differences among stakeholder groups (Fig. 4). Consensus for culling at the den and trapping or snaring was moderate to low for farmers-hunters $\left(\mathrm{PCI}_{2}=0.67\right.$ and 0.65 , respectively), hunters $\left(\mathrm{PCI}_{2}=0.53\right.$ and 0.57 , respectively), and farmers $\left(\mathrm{PCI}_{2}=0.42\right.$ and 0.29 , respectively $)$, and high for the general public $\left(\mathrm{PCI}_{2}=0.13\right.$ and 0.08 , respectively), with differences being significant between the general public and all other groups and between farmers-hunters and farmers $(p<0.0083)$. Consensus for hunting foxes when they reduce game was generally high, with differences being significant between hunters $\left(\mathrm{PCI}_{2}=0.25\right)$ and the general public $\left(\mathrm{PCI}_{2}=0.12\right)(p<0.0083$; $d$ tests with Bonferroni correction). Consensus for shooting foxes was low within the farmer-hunter $\left(\mathrm{PCI}_{2}=0.63\right)$ and hunter $\left(\mathrm{PCI}_{2}=0.70\right)$ groups and high within the farmer $\left(\mathrm{PCI}_{2}=0.36\right)$ and especially the general public $\left(\mathrm{PCI}_{2}=\right.$ $0.06)$ groups. Differences in $\mathrm{PCI}_{2}$ values were significant among all groups, except between farmers-hunters and hunters $(p<0.0083)$.

\section{Scenario 3: Foxes carry rabies}

In this severe scenario, taking no action was unacceptable and vaccination acceptable for all stakeholder groups with no significant differences among them (Table 3, Fig. 5). Killing rabid foxes was also acceptable, being significantly more acceptable for farmers-hunters $(M=0.88)$ and farmers $(M=0.80)$ than the general public $(M=0.12)(p<0.0083$; Tamhane post hoc tests with Bonferroni correction). Culling at the den was significantly more unacceptable for the general public $(M=$ - 0.97) than for farmers $(M=-0.18)$, hunters $(M=$ $0.63)$, and farmers-hunters $(M=0.41)(p<0.0083)$. Trapping or snaring $(M=-1.27,-0.90,0.36$, and 0.65 for the general public, farmers, hunters, and farmershunters, respectively), hunting $(M=-1.01,-0.52,0.88$, and 1.18 for the general public, farmers, hunters, and

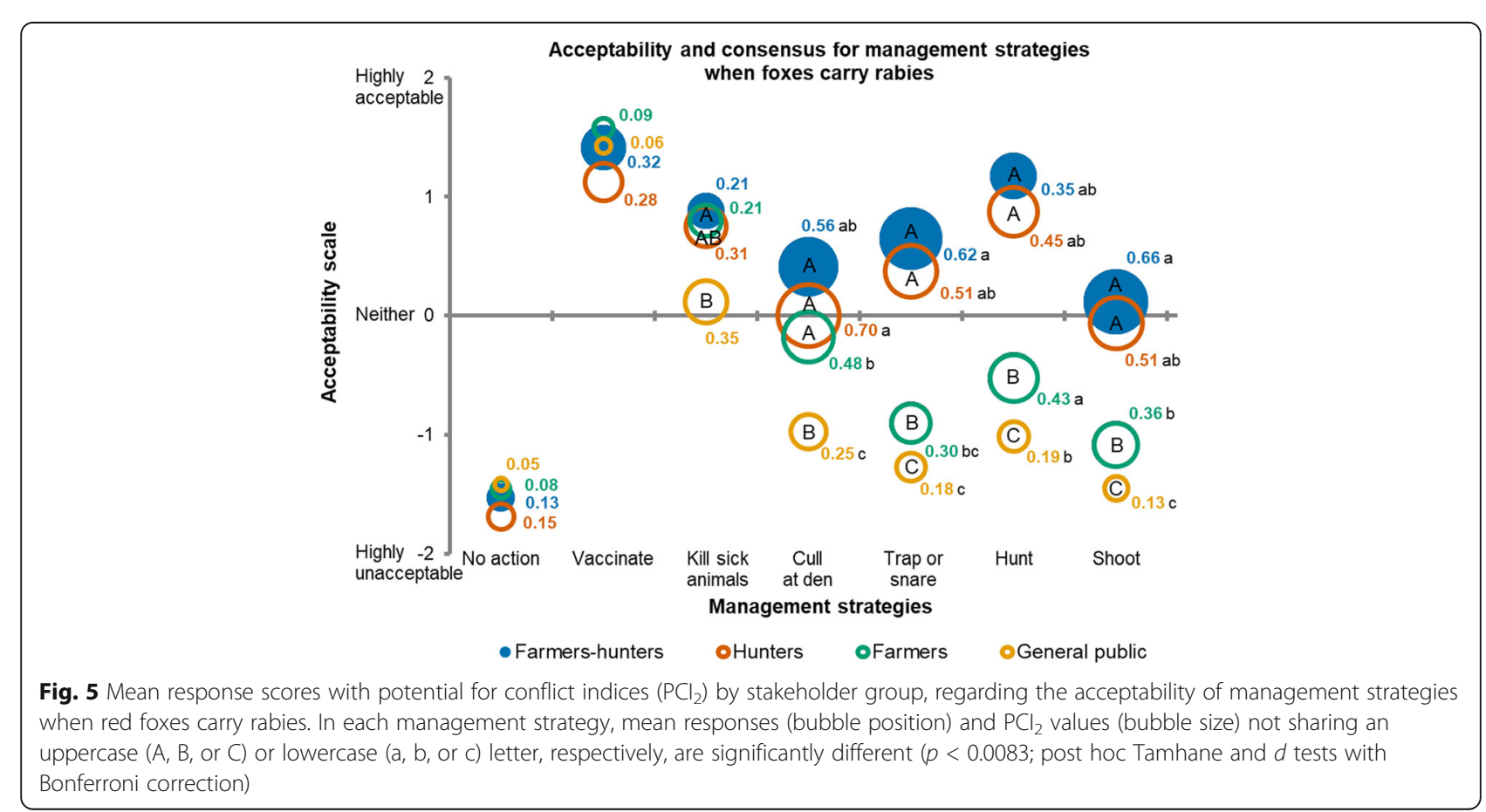


farmers-hunters, respectively), and shooting ( $M=-1.45$, - 1.08, - 0.06, and 0.12 for the general public, farmers, hunters, and farmers-hunters, respectively) were significantly more acceptable for farmers-hunters and hunters than for farmers and the general public, and also for farmers than the general public $(p<0.0083)$. The level of consensus was generally high for taking no action $\left(\mathrm{PCI}_{2}=\right.$ $0.05-0.15)$, vaccination $\left(\mathrm{PCI}_{2}=0.06-0.32\right)$, and the killing of sick animals $\left(\mathrm{PCI}_{2}=0.21-0.35\right)$, with no significant differences among stakeholder groups (Fig. 5). Consensus for culling at the den was moderate to low, being significantly higher for the general public $\left(\mathrm{PCI}_{2}=0.25\right)$ than for farmers $\left(\mathrm{PCI}_{2}=0.48\right)$, hunters $\left(\mathrm{PCI}_{2}=0.70\right)$, and farmers-hunters $\left(\mathrm{PCI}_{2}=0.56\right)$, and for farmers than hunters $(p<0.0083$; $d$ tests with Bonferroni correction). Consensus for trapping or snaring was moderate to low for farmers-hunters $\left(\mathrm{PCI}_{2}=0.62\right)$ and hunters $\left(\mathrm{PCI}_{2}=\right.$ $0.51)$ and high for farmers $\left(\mathrm{PCI}_{2}=0.30\right)$ and the general public $\left(\mathrm{PCI}_{2}=0.18\right)$, with differences being significant between farmers-hunters and both farmers and the general public and between the latter and hunters $(p<0.0083)$. Level of consensus for hunting rabid foxes was significantly higher for the general public $\left(\mathrm{PCI}_{2}=0.19\right)$ than farmers $\left(\mathrm{PCI}_{2}=0.43\right)(p<0.0083)$. Consensus for shooting rabid foxes was significantly higher for the general public $\left(\mathrm{PCI}_{2}=0.13\right)$ than for farmers $\left(\mathrm{PCI}_{2}=0.36\right)$, hunters $\left(\mathrm{PCI}_{2}=0.51\right)$, and farmers-hunters $\left(\mathrm{PCI}_{2}=0.66\right)$, and for farmers than farmers-hunters $(p<0.0083)$.

\section{Differences within stakeholder groups across scenarios}

Taking no action was more unacceptable in the most severe scenario 3 , foxes carry rabies (Table 4 ). Differences were significant between scenario $3(M=-1.69)$, and scenario 1 , foxes attack livestock $(M=-0.75)$, for hunters and among all the scenarios for the general public $(M=-0.60,0.28$, and -1.41 for scenarios 1,2 , foxes reduce game, and 3 , respectively) and farmers $(M=-0.96,-0.38$, and -1.46 for scenarios 1,2 , and 3 respectively) ( $p<0.001$, Tamhane post hoc tests with Bonferroni correction, Table 4). Culling at the den was significantly less unacceptable in scenario 3 than in scenarios 1 and 2 for the general public $(M=$ -1.42 , -1.38 , and -0.97 for scenarios 1,2 , and 3 , respectively) and farmers $(M=-0.79,-0.72$, and -0.18 for scenarios 1,2 , and 3 , respectively) ( $p<0.001$ ). Trapping or snaring was significantly less unacceptable in

Table 4 Comparisons of acceptability within impact scenarios for each of the management strategies and stakeholder groups $(n=746)$

\begin{tabular}{|c|c|c|c|c|c|c|c|}
\hline $\begin{array}{l}\text { Strategy/ } \\
\text { scenario } \\
\end{array}$ & $\begin{array}{l}\text { General public } \\
(\mathrm{M})\end{array}$ & $\begin{array}{l}\text { Farmers } \\
(\mathrm{M})\end{array}$ & $\begin{array}{l}\text { Hunters } \\
(\mathrm{M})\end{array}$ & $\begin{array}{l}\text { Farmers-hunters } \\
\text { (M) }\end{array}$ & $\begin{array}{l}\text { Multivariate } \\
\text { Wilks' } \lambda\end{array}$ & $\begin{array}{l}\text { Within-subject Greenhouse- } \\
\text { Geisser }\end{array}$ & $\begin{array}{l}\text { Partial eta squared } \\
\left(\eta_{p}^{2}\right)\end{array}$ \\
\hline \multicolumn{8}{|l|}{ No action } \\
\hline Scenario 1 & $-0.60^{A}$ & $-0.96^{A}$ & $-0.75^{A}$ & $-1.35^{A}$ & $49.301^{*}$ & $89.793^{*}$ & 0.137 \\
\hline Scenario 2 & $0.28^{B}$ & $-0.38^{B}$ & $-1.13^{A B}$ & $-1.47^{\mathrm{A}}$ & & & \\
\hline Scenario 3 & $-1.41^{c}$ & $-1.46^{c}$ & $-1.69^{B}$ & $-1.53^{A}$ & & & \\
\hline \multicolumn{8}{|c|}{ Culling at the den } \\
\hline Scenario 1 & $-1.42^{A}$ & $-0.79^{A}$ & $-0.31^{\mathrm{A}}$ & $-0.29^{A}$ & $29.819^{*}$ & $54.512^{*}$ & 0.090 \\
\hline Scenario 2 & $-1.38^{A}$ & $-0.72^{A}$ & $0.38^{A}$ & $0.53^{A}$ & & & \\
\hline Scenario 3 & $-0.97^{B}$ & $-0.18^{B}$ & $0.00^{\mathrm{A}}$ & $0.41^{\mathrm{A}}$ & & & \\
\hline \multicolumn{8}{|c|}{ Trapping or snaring } \\
\hline Scenario 1 & $-1.63^{A}$ & $-1.09^{A}$ & $-0.31^{\mathrm{A}}$ & $-0.18^{A}$ & $25.131^{*}$ & $31.368^{*}$ & 0.073 \\
\hline Scenario 2 & $-1.50^{\mathrm{A}}$ & $-1.10^{A}$ & $0.19^{A}$ & $0.24^{\mathrm{A}}$ & & & \\
\hline Scenario 3 & $-1.27^{B}$ & $-0.90^{\mathrm{A}}$ & $0.36^{\mathrm{A}}$ & $0.65^{\mathrm{A}}$ & & & \\
\hline \multicolumn{8}{|l|}{ Hunting } \\
\hline Scenario 1 & $-1.32^{A}$ & $-0.87^{A}$ & $-0.19^{A}$ & $0.00^{A}$ & $47.730^{*}$ & $83.901^{*}$ & 0.137 \\
\hline Scenario 2 & $-1.32^{A}$ & $-0.81^{A}$ & $1.31^{\mathrm{B}}$ & $1.41^{\mathrm{B}}$ & & & \\
\hline Scenario 3 & $-1.01^{B}$ & $-0.52^{A}$ & $0.88^{B}$ & $1.18^{\mathrm{B}}$ & & & \\
\hline \multicolumn{8}{|l|}{ Shooting } \\
\hline Scenario 1 & $-1.62^{A}$ & $-1.44^{\mathrm{A}}$ & $-1.00^{\mathrm{A}}$ & $-0.71^{A}$ & $43.271^{*}$ & $50.622^{*}$ & 0.123 \\
\hline Scenario 2 & $-1.57^{A}$ & $-1.17^{A B}$ & $-0.19^{A B}$ & $0.41^{B}$ & & & \\
\hline Scenario 3 & $-1.45^{\mathrm{A}}$ & $-1.08^{B}$ & $-0.06^{B}$ & $0.12^{A B}$ & & & \\
\hline
\end{tabular}

Note: Repeated measures analysis of variance was used for comparisons. Scenario 1, foxes attack livestock; scenario 2 , foxes reduce game; scenario 3 , foxes carry rabies. $M=$ mean acceptability. Partial eta-squared $\left(\eta_{\mathrm{p}}{ }^{2}\right)$, effect size, $\eta_{\mathrm{p}}{ }^{2}=0.01-0.059$ denotes a small effect, $\eta_{\mathrm{p}}{ }^{2}=0.06-0.139$ denotes a medium effect, $\eta_{\mathrm{p}}{ }^{2}>0.14$ denotes a large effect (Vaske 2008). In each management strategy and stakeholder group, scenarios' mean scores not sharing a superscript letter (A, B, or C) are significantly different $\left(p<0.0167\right.$, Tamhane post hoc tests with Bonferroni correction). ${ }^{*} p<0.001$ 
scenario 3 than in scenarios 1 and 2 for the general public $(M=-1.63,-1.50$, and -1.27 for scenarios 1,2 , and 3 , respectively) $(p<0.0083)$. Hunting was significantly more acceptable in scenarios 2 and 3 than in scenario 1 for farmers-hunters $(M=0.00$, 1.41 , and 1.18 for scenarios 1,2 , and 3 , respectively) and hunters $(M=-0.19,1.31$, and 0.88 for scenarios 1,2 , and 3 , respectively), and also less unacceptable in scenario 3 than in both other scenarios for the general public $(M=-1.32,-1.32$, and -1.01 for scenarios 1,2 , and 3 , respectively) $(p<0.001)$. Shooting was more acceptable in scenario 2 than in scenario 1 for farmers-hunters $(M=-0.71$ and 0.41 for scenarios 1 and 2, respectively) and in scenario 3 than in scenario 1 for hunters $(M=-1.00$ and -0.06 for scenarios 1 and 3, respectively) and farmers $(M=-1.44$ and -1.08 for scenarios 1 and 3 , respectively) $(p<0.001)$.

\section{Discussion}

\section{Preferences for fox management}

Across scenarios, survey participants accepted the less invasive nonlethal strategies and rejected lethal strategies. However, they accepted the removal of sick animals to prevent rabies infection. In addition to being less acceptable, more invasive methods were also more controversial among participants (i.e., had higher $\mathrm{PCI}_{2}$ values) than less invasive methods. The differences in the mean acceptability and consensus found between nonlethal and lethal strategies supported our hypothesis 2: "Acceptability and consensus both decrease with increasing invasiveness of the management strategies." Similar results have also been reported by previous studies (Sponarski et al. 2015; Liordos et al. 2017; Heneghan and Morse 2019). Among scenarios, doing nothing was becoming more unacceptable and lethal strategies (i.e., culling at the den, trapping or snaring, hunting, and shooting) more acceptable with increasing severity of the impact, i.e., livestock and game predation versus rabies transmission. Lethal strategies were also becoming more controversial among participants with increasing severity of the impact. These results mostly supported our hypothesis 3: "Acceptability increase and consensus decrease for each management strategy with increasing severity of the impact." Similar to our results, many other studies have found that the acceptability of and consensus for management strategies vary by situational context (e.g., Jacobs et al. 2014; Sponarski et al. 2015; Liordos et al. 2017; Doney et al. 2018; Heneghan and Morse 2019).

Stakeholder groups involving a farmer and/or hunter identity were more negative than the general public in doing nothing to prevent livestock predation by foxes and also more accepting, although generally neutral to negative, towards lethal strategies. All stakeholder groups accepted compensation and more strongly fencing for managing livestock predation, vaccination, and the killing of sick animals to prevent rabies transmission. The general public accepted taking no action for preventing fox predation on the game. On the contrary, groups with a hunting identity were the most opposing to doing nothing, and at the same time, they accepted the implementation of lethal strategies when foxes reduce game or carry rabies, with hunting being their favorite strategy. Consensus regarding fox management was higher for the no action and nonlethal strategies and lower for lethal strategies. Differences between $\mathrm{PCI}_{2}$ values showed that consensus was missing both within and between groups in all scenarios. Within groups, the potential for conflict was high in hunters and farmershunters for the lethal strategies, i.e., culling at the den, trapping or snaring, hunting, and shooting in all scenarios. Between groups, the potential for conflict was higher between the general public and all other groups in all scenarios, especially for the lethal strategies. The differences in the mean acceptability of and consensus for management strategies found among stakeholder groups supported our hypothesis 1: "Acceptability and consensus both differ between stakeholder groups in each management strategy." It should be noted that when farmers were asked about their acceptability of and consensus for different management strategies when foxes attack livestock, it had not been taken into consideration whether they had or had not suffered losses by foxes. Although foxes abound in the study area and the possibility of depredation always exists, opinions might vary among farmers depending on the incident occurrence. Also, foxes mostly prey on brown hares and grey partridges in Greece. Hunters of these species might display more negative attitudes towards foxes than hunters of other game species, such as wild boars, woodpigeons (Columba palumbus), or waterfowl. Such limitations should be considered before drawing conclusions and generalizing findings.

Other studies have also found that farmers and hunters are generally more positive towards lethal control compared to other strategies and to the preferences of the general public, especially when wildlife species threaten their livelihoods and game. Non-selective strategies, such as some types of snares, were the most preferred strategy for fox control by managers in commercial game estates in Central Spain (Delibes-Mateos et al. 2013). The general public in Central Italy was in favor of using preventive strategies and compensation for the ecological and economic damage of wild boars, provided they did not directly impact wild boar numbers, whereas farmers, the group most impacted by wild boar damages, supported all strategies suitable for the alleviation of wild boar damage on crops (Frank et al. 
2015). Black bear (Ursus americanus) hunters in Central Georgia (Agee and Miller 2009) and wild boar hunters in Central Italy (Frank et al. 2015) did not accept lethal control of their game to reduce negative impacts; however, black bear hunters in Wisconsin supported lethal control of grey wolves (Canis lupus) when they attacked their hunting dogs (Naughton-Treves et al. 2003). Although Greek farmers displayed more positive attitudes toward lethal strategies when compared to other groups, they were still reluctant to adopt them. It seemed that they considered fencing and compensation sufficient to address the issue.

Fencing is considered effective for the protection of livestock from foxes if properly installed (Macdonald et al. 2000), and it is commonly used to exclude foxes and other predators in Greece. Greek legislation predicts compensation for damage to livestock by grey wolves and brown bears (Ursus arctos), but not by foxes. However, an application for compensation could be considered under the framework of reimbursements of damage to crops by wildlife, although with uncertain outcome (ELGA 2019). Hunters seemed determined to reduce impacts themselves, since they strongly preferred hunting to other strategies for controlling fox predation on the game, mostly brown hare. However, there is not a foxhunting culture in Greece and although fox hunting is permitted from 15 September to 28 February, they are not generally targeted by Greek hunters. Fox hunting interest is greater in periods of brown hare decline or following rabies incidents. Shooting, hunting, and the removal of cubs and vixen from dens are the most common strategies used to reduce fox predation on livestock and game (Harris 1985; Heydon and Reynolds 2000; Macdonald et al. 2000). Trapping, snaring, and poison baiting are non-selective strategies, meaning they could also harm non-target species such as badgers, martens, kites; when used, efforts should be made to increase their selectivity (Macdonald et al. 2000; Birtsas et al. 2008). The use of non-locking neck snares and cage or box traps is allowed in the European Union, while poison baiting is illegal (Macdonald et al. 2000; Birtsas et al. 2008).

Stakeholders strongly supported acting against rabid foxes. They strongly supported vaccination programs, followed by the removal of sick animals. Lethal control strategies, especially hunting, were more accepted by hunters. The severity of the situation called for immediate action, and the general public rather considered that vaccination would suffice. Farmers and hunters also supported vaccination, but further considered the killing of sick animals a necessary action. Oral vaccination programs have proved effective in eradicating rabies from Western and Central Europe (Freuling et al. 2013). Tsiodras et al. (2013) proposed that the effectiveness of vaccination would increase if combined with strategies to reduce fox population densities. Hunters might be more supportive of lethal control probably because they perceive rabies, in addition to public health, as a threat to their game. Then again, hunters are consumptive users of wildlife resources sharing a utilitarian disposition toward animals, and as such, they are generally more supportive of lethal control of problem wildlife than other interest groups (Kellert 1980; NaughtonTreves et al. 2003).

Even if the most suitable strategies for reducing fox impacts have been selected and appropriately implemented, they could prove ultimately ineffective when they are not combined with prey habitat management. Panek (2009) found that fox predation on brown hares decreased with increasing habitat diversity. He also showed that the relationship between the number of prey consumed and the density of the prey population is sigmoidal, meaning that foxes will drop hunting efforts on brown hares when they occur in low densities, thus preventing their extinction.

\section{Conservation conflict management recommendations}

Papageorgiou et al. (1988) found that small rodents were the main prey of foxes in Greece, followed by lambs, piglets, calves, and goat kids in lower proportions, whereas Vlachos et al. (2006) found a prevalence of brown hares in fox diet. Fox rabies reemerged in Greece in 2012 (Tsiodras et al. 2013). Complaints by farmers and hunters about considerable damage to livestock and game are currently increasing in north Greece, suggesting that conservation conflicts, conflicts between stakeholder groups over wildlife issues, have emerged. Considerable variation was observed in the acceptability of and the consensus for management strategies among stakeholder groups in all the scenarios. The high potential for conflict between stakeholder groups and, most importantly, within the groups more exposed to wildlife impacts, i.e., those with hunter and/or farmer identity, suggested that "human-human conflicts" need to be firstly resolved to achieve effective fox impact management (Marshall et al. 2007).

Our findings should be communicated to stakeholders through the design of appropriate outreach programs (Jacobson et al. 2015; Agwu et al. 2018). Farmers and hunters are those directly affected by fox predation. Meetings with farmers and hunters should be organized, at the offices of local farmers' cooperatives and hunting clubs. The general public is more concerned about health issues. Relevant information could be communicated through the arrangement of public meetings at municipal halls. The most acceptable and less controversial among the management strategies, as identified by our study, should be prioritized and explicated during these meetings. Those were fencing and compensation 
when foxes attack livestock, hunting when foxes reduce game and vaccination and the killing of sick animals when foxes carry rabies. Other strategies, such as culling at the den and trapping, could be put forth and elaborated if deemed more effective. Factsheets and brochures, laying out the facts and explaining appropriate management strategies, should also be distributed to stakeholders to promote the understanding of the situation. Posters, news releases, and opinion articles could also be used to reach a wider audience. Sometimes people are not persuaded by facts, but their opinions and decisions are mostly affected by their personal worldviews and experience. Therefore, the outcomes of outreach activities should be evaluated.

Communication and outreach activities could be integrated into and inform a participatory process that includes the engagement of stakeholders in conservation conflict management groups aiming at finding shared solutions to reduce negative impacts (Redpath et al. 2013). Stakeholder groups involved in the conservation conflicts are farmers, hunters, environmental nongovernmental organizations (NGOs), animal welfare groups, and members of the general public. Third parties that could improve engagement are government representatives and scientists that evaluate impacts (Frodeman et al. 2017). Proper implementation of the conservation conflict management process should help mitigate the potentially negative impacts of foxes on livestock, game, and human and animal health and at the same time achieve the conservation of healthy fox populations. The Forest Service is responsible for wildlife management, hunting regulation, and land use classification in Greece. This might have led to conflicts and distrust with stakeholder groups, such as farmers and hunters. Therefore, it would be preferable independent scientists, employed by the Ministry of Environment and Energy, to serve as facilitators to the process.

\section{Conclusions}

Our findings offer an important guide for managing conflicts between stakeholders and reducing fox impacts on livestock, game, and human and animal health, as the most preferred and least controversial management strategies have been identified. Future research should investigate fox impacts on livestock and game and monitor and evaluate rabies incidents for establishing impact severity. When a considerable level of impact is determined, the application of the most effective and least controversial management strategies should be proposed. Human conflicts over wildlife include two components: (a) human-wildlife impacts, which focus on the direct interactions between humans and other species (Woodroffe et al. 2005), and (b) the underlying humanhuman conflicts between those seeking to conserve species versus those with other interests (Young et al. 2010). We suggested using the framework proposed by Redpath et al. (2013) for managing conservation conflicts, aimed at reducing wildlife impacts on human activities, minimizing social conflicts, and protecting wildlife populations. However, a conservation conflict would not be successfully addressed before all stakeholder groups support the implementation of a management plan (Redpath et al. 2015). Therefore, our findings about stakeholders' preferences and consensus for management strategies could be critical for informing the conservation conflict management process. Further recommendations for improving the process include the following:

1) Farmers and hunters might have opposing opinions to other stakeholder groups such as environmental NGOs and animal welfare groups. The former might prioritize the protection of livestock and game, whereas the latter the protection of wildlife species. Strongly opposing opinions and worldviews often lead to distrust between parties, a main barrier to collaboration. Facilitators should integrate all stakeholders on an equal footing, in an effort to build trust between the parties and to the process. Young et al. (2016) presented evidence that increased trust through fairness in public participation, meaning that all relevant stakeholders are represented and that procedures enable them to have an input into the format and content of discussions, makes conflict resolution more likely.

2) Scientists are an important third party to the conflict management process. They are responsible for quantifying impacts and suggesting effective management strategies. Their role is complex as much as important; they must try to build trust with parties by remaining unbiased and avoiding favoring sides (Treves et al. 2006).

3) The process should not discuss unrealistic goals in an effort to satisfy all parties, but to seek, through dialogue and compromise, the optimal solution (Peterson et al. 2010).

4) The media could exacerbate conflicts to attract public attention. Good media relationships are therefore critical for the conflict management process (Barua 2010).

Foxes have a wide distribution across most of the northern hemisphere and were also introduced elsewhere (Wilson and Mittermeier 2009). Therefore, implications from this study might also prove useful for other areas where similar fox impacts occur. Rabies does persist in many countries, including neighboring to Greece Balkan and Asia Minor countries, such as Bulgaria, the 
Republic of North Macedonia, and Turkey (Tasioudi et al. 2014). Fox impacts on livestock and game have been recorded throughout the species' range. However, our findings would be more readily applicable in areas within fox's native range, particularly in European and most importantly in Mediterranean countries with social and ecological conditions similar to Greece's, such as Italy, France, and Spain (Delibes-Mateos et al. 2013).

\section{Acknowledgements}

We thank survey participants for sharing their time and opinion with us. We also thank two anonymous reviewers whose comments and suggestions helped greatly improve this manuscript.

\section{Authors' contributions}

$V L$ designed the study, performed the statistical analysis, and wrote the first draft. VJK designed the study, assisted in the statistical analysis, and collected literature. FE contributed to the survey methodology and performed data collection and entry. All authors helped in writing and editing the manuscript. All authors read and approved the final manuscript.

\section{Funding}

Not applicable.

\section{Availability of data and materials}

The datasets generated and analyzed during the current study are available from the corresponding author on reasonable request.

\section{Ethics approval and consent to participate}

We performed all research methods in accordance with the relevant guidelines and regulations laid out by the International Hellenic University Research and Academic Committee with respect to the study of human participants. Participants, after having received and understood all researchrelated information, willingly participated in the survey. We maintained anonymity of the human respondents at all the stages of the research.

\section{Consent for publication}

Not applicable.

\section{Competing interests}

The authors declare that they have no competing interests.

Received: 1 January 2020 Accepted: 10 March 2020 Published online: 01 May 2020

\section{References}

Agee JD, Miller CA (2009) Factors contributing toward acceptance of lethal control of black bears in Central Georgia, USA. Hum Dimens Wildl 14:198-205

Agwu OP, Bakayoko A, Jimoh SO, Porembski S (2018) Farmers' perceptions on cultivation and the impacts of climate change on goods and services provided by Garcinia kola in Nigeria. Ecol Process 7:36

Barua M (2010) Whose issue? Representations of human-elephant conflict in Indian and international media. Sci Commun 32:55-75

Birtsas P, Sokos C, Kastoris A (2008) Reduction of predation by fox (Vulpes vulpes): indirect techniques. In: Mantzanas KT, Papanastasis VP (eds) Proceedings of the 6th Panhellenic Rangeland Congress. Leonidio, Greece, pp 281-286

Delibes-Mateos M, Díaz-Fernández S, Ferreras P, Viñuela J, Arroyo B (2013) The role of economic and social factors driving predator control in small-game estates in central Spain. Ecol Soc 18:28

Doney ED, Bath AJ, Vaske JJ (2018) Understanding conflict and consensus regarding wood bison management in Alaska, USA. Wildl Res 45:229-236

ELGA (Greek Agricultural Insurance Organisation) (2019). Insurance and financial support. http://www.elga.gr/asfalisi-kai-enisxyseis. Accessed 15 Nov 2019

ELSTAT (Hellenic Statistical Authority) (2011). Population Census 2011. http:// www.statistics.gr/portal/page/portal/ESYE/PAGE-census2011. Accessed 15 Nov 2019
Engel MT, Vaske JJ, Bath AJ, Marchini S (2017) Attitudes toward jaguars and pumas and the acceptability of killing big cats in the Brazilian Atlantic Forest: an application of the Potential for Conflict Index. Ambio 46:604-612

Frank B, Monaco A, Bath AJ (2015) Beyond standard wildlife management: a pathway to encompass human dimension findings in wild boar management. Eur J Wildl Res 61:723-730

Freuling CM, Hampson K, Selhorst T, Schröder R, Meslin FX, Mettenleiter TC, Müller T (2013) The elimination of fox rabies from Europe: determinants of success and lessons for the future. Philos Trans R Soc Lond B 368:20120142

Frodeman R, Thompson Klein J, Pacheco RCS (2017) The Oxford Handbook of Interdisciplinarity, 2nd edn. Oxford University Press, Oxford

Harris S (1985) Humane control of foxes. In: Britt DP (ed) Humane control of land mammals and birds. The Universities, Federation for Animal Welfare, Potters Bar, pp 63-74

Harris S, Lloyd HG (1991) Fox Vulpes vulpes. In: Corbet GB, Harris S (eds) The Handbook of British Mammals. Blackwell Science Publications, Oxford, pp 351-367

Heneghan MD, Morse WC (2019) Acceptability of management actions and the potential for conflict following human-black bear encounters. Soc Nat Resour 32:434-451

Heydon MJ, Reynolds JC (2000) Fox (Vulpes vulpes) management in three contrasting regions of Britain, in relation to agricultural and sporting interests. J Zool 251:237-252

Jacobs MH, Vaske JJ, Sijtsma MTJ (2014) Predictive potential of wild life value orientations for acceptability of management interventions. J Nat Conserv 22: 377-383

Jacobson SK, McDuff MD, Monroe MC (2015) Conservation education and outreach techniques, 2nd edn. Oxford University Press, Oxford

Kellert S (1980) American's attitudes toward and knowledge of animals: an update. Int J Study Anim Probl 1:7-119

König A (2008) Fears, attitudes and opinions of suburban residents with regards to their urban foxes: a case study in the community of Grünwald — - a suburb of Munich. Eur J Wildl Res 54:101-109

Kontsiotis VJ, Vadikolios G, Liordos V (2020) Acceptability and consensus for the management of game and nongame crop raiders. Wildl Res (in press)

Krymkowski DH, Manning RE, Valliere WA (2009) Norm crystallization: measurement and comparative analysis. Leis Sci 31:403-416

Liordos V, Kontsiotis VJ, Georgari M, Baltzi K, Baltzi I (2017) Public acceptance of management methods under different human-wildlife conflict scenarios. Sci Total Environ 579:685-693

Macdonald DW, Tattersall FH, Johnson PJ, Carbone C, Reynolds JC, Langbein J, Rushton SP, Shirley MDF (2000) Management and control of populations of foxes, deer, hares and mink in England and Wales, and the impact of hunting with dogs. A report to the Committee of Inquiry into Hunting with Dogs. The Stationery Office, London

Madden F (2004) Creating coexistence between humans and wildlife: global perspectives on local efforts to address human-wildlife conflict. Hum Dimens Wildl 9:247-257

Manfredo MJ (2008) Who cares about wildlife? Springer, New York

Marshall K, White R, Fischer A (2007) Conflicts between humans over wildlife management: on the diversity of stakeholder attitudes and implications for conflict management. Biodivers Conserv 16:3129-3146

Naughton-Treves L, Grossberg R, Treves A (2003) Paying for tolerance: rural citizens' attitudes toward wolf depredation and compensation. Conserv Biol 17:1500-1511

O'Mahony D, Lambin X, Mackinnon JL, Coles CF (1999) Fox predation on cyclic field vole populations in Britain. Ecography 22:575-581

Pagh S, Tjørnløv RS, Olesen CR, Chriel M (2015) The diet of Danish red foxes (Vulpes vulpes) in relation to a changing agricultural ecosystem. A historical perspective. Mammal Res 60:319-329

Panek M (2009) Factors affecting predation of red foxes Vulpes vulpes on brown hares Lepus europaeus during the breeding season in Poland. Wildl Biol 15: $345-349$

Papageorgiou NK, Sfougaris Al, Christopoulou OG, Vlachos CG, Petamidis JS (1988) Food habits of the red fox in Greece. Acta Theriol 33:313-324

Peterson MN, Birckhead JL, Leong K, Peterson MJ, Peterson TR (2010) Rearticulating the myth of human-wildlife conflict. Conserv Lett 3:74-82

Redpath SM, Bhatia S, Young J (2015) Tilting at wildlife: reconsidering humanwildlife conflict. Oryx 49:222-225

Redpath SM, Young J, Evely A, Adams WM, Sutherland WJ, Whitehouse A, Amar A, Lambert RA, Linnell JDC, Watt A, Gutiérrez RJ (2013) Understanding and managing conservation conflicts. Trends Ecol Evol 28:100-109 
Sponarski CC, Vaske JJ, Bath AJ (2015) Differences in management action acceptability for coyotes in a National Park. Wildl Soc Bull 39:239-247

Tasioudi KE, lliadou P, Agianniotaki El, Robardet E, Liandris E, Doudounakis S, Tzani M, Tsaroucha P, Picard-Meyer E, Cliquet F, Mangana-Vougiouka O (2014) Recurrence of animal rabies, Greece, 2012. Emerg Infect Dis 20:326-328

Treves A, Wallace RB, Naughton-Treves L, Morales A (2006) Co-managing human-wildlife conflicts: a review. Hum Dimens Wildl 11:383-396

Tsiodras S, Dougas G, Baka A, Billinis C, Doudounakis S, Balaska A, Georgakopoulou T, Rigakos G, Kontos V, Tasioudi KE, Tzani M, Tsarouxa P, Iliadou P, Mangana-Vougiouka O, Iliopoulos D, Sapounas S, Efstathiou P, Tsakris A, Hadjichristodoulou C, Kremastinou J (2013) Re-emergence of animal rabies in northern Greece and subsequent human exposure, October 2012 - March 2013. Euro Surveill 18:20474

Vaske JJ (2008) Survey research and analysis: applications in parks, recreation and human dimensions. Venture Publishing, State College

Vaske JJ, Beaman J, Barreto H, Shelby LB (2010) An extension and further validation of the Potential for Conflict Index. Leis Sci 32:240-254

Vlachos C, Bakaloudis DE, Hatzinikos EN (2006) Red fox and stone marten predation on wildlife. 4th Hunting Federation of Central Greece, Thessaloniki

Wilson DE, Mittermeier RA (eds) (2009) Handbook of the mammals of the world. Volume 1 of carnivores. Lynx Edicions, Barcelona

Woodroffe R, Thirgood S, Rabinowitz A (eds) (2005) People and wildlife: conflict or co-existence? Cambridge University Press, Cambridge

Young JC, Marzano M, White RM, McCracken DI, Redpath SM, Carss DN, Quine CP, Watt AD (2010) The emergence of biodiversity conflicts from biodiversity impacts: characteristics and management strategies. Biodivers Conserv 19: 3973-3990

Young JC, Searle K, Butler A, Simmons P, Watt AD, Jordan A (2016) The role of trust in the resolution of conservation conflicts. Biol Conserv 195:196-202

\section{Publisher's Note}

Springer Nature remains neutral with regard to jurisdictional claims in published maps and institutional affiliations.

\section{Submit your manuscript to a SpringerOpen ${ }^{\circ}$ journal and benefit from:}

- Convenient online submission

- Rigorous peer review

- Open access: articles freely available online

- High visibility within the field

- Retaining the copyright to your article

Submit your next manuscript at $\boldsymbol{\nabla}$ springeropen.com 